\title{
Towards a Better Understanding of Project Management Assets and Employee Performance of Quality: An Empirical Study Within State-Owned Enterprises (SOEs) in the UAE
}

\author{
${ }^{1}$ Mohammad Khalifa Al Falasi, ${ }^{2}$ Mohammed Saleh Nusari, ${ }^{3}$ Gamal S.A. Khalifa, \\ ${ }^{1}$ Ali Ameen and ${ }^{1}$ Osama Issac \\ ${ }^{1}$ Faculty of Business and Accountancy, \\ ${ }^{2}$ Faculty of Engineering, \\ ${ }^{3}$ Faculty of Hospitality and Tourism, Lincoln University College, Selangor, Malaysia
}

\begin{abstract}
In today's competitive business environment, organizations are focusing on project management assets which are becoming an integral part of every aspect and activity and thus has a profound impact on the performance of the employees. State Owned Enterprises (SOE) of Abu Dhabi are the focus of this study as they are considered the key economic power-house both at the local and federal government levels. Applying a resource-based analysis, namely the VRIO framework (VRIO is an acronym for Value, Rarity, Imitability and Organisation) to examine the effect of these assets on employees performance in terms of quality. The data was collected from 539 employees of State Owned Enterprises (SOE) of Abu Dhabi and analysed using Structural Equation Modelling (SEM) via. SmartPLS 3.0. There were two main results first, value, rarity, imitability and organization have a positive impact on quality second, the proposed model explained $61 \%$ of the variance in quality. Theoretical and practical implications are also provided.
\end{abstract}

Key words: Project management assets, employee performance, state-owned enterprises, VRIO, UAE, SOE

\section{INTRODUCTION}

Although, there is an increased focus on project management assets as a tool to enhance the competitiveness of organizations, however, it lacks the same attention in the academic literature where the main focus is on the effect of operational aspects on employee performance (Mathur et al., 2014). Achieving greater performance is at the heart of the existence of every entity and it can be attained through different ways (Aldholay et al., 2018a-c). Some organizations think of their internal capabilities while others account on their external position. We assess the process of project management from resource-based view perspective, considering that project management process represents a subset of the resources which may include a source of competitive advantage. Traditionally in their quest for project success, project managers are faced with crucial challenges to overcome such as virtually managed project teams, clearly defined project goals, high project transparency, adequate control methods, predefined project methods, communication efficiencies and sufficient risk management (Pander and Wagner). Project objectives and project management in general has transpired with little consideration of key project stakeholders. As stressed by Comu et al. (2010), future business management would involve network organizational structures and virtual development teams in the course of produce development.

According to the literature of project management assets, a source of competitive advantage can be resources or any assets provided being characterised as having economic Value (V), Rare (R), Inimitable (I) and they have Organizational support $(\mathrm{O})$ to leverage these assets (Barney, 1991; Barney and Hesterly, 2014). In an integrated theoretical framework referred to as the VRIO framework, a resource that has organizational support contributes to competitive parity by being valuable, it contributes to temporary competitive advantage if it is both valuable and rare and it provides sustained competitive advantage if it is valuable, rare and inimitable.

The context of this study is State Owned Enterprises (SOEs) of Abu Dhabi Emirate. They are the key economic power-house both at the local and federal government levels. To shed more light on the background of the SOEs, their diversity in terms of culture and orientation to all project management assets of value (Barney and Hesterly, 2014), rarity (Tuan and Yoshi, 2010), imitability (Barney,

Corresponding Author: Mohammad Khalifa Al Falasi, Faculty of Business and Accountancy, Lincoln University College, Selangor, Malaysia 
1991 ) and organization (Barney and Hesterly, 2014) have been associated with organizational level u management in the form of projects, it may be noted that the United Arab Emirates (UAE) after gaining independence in 1971 has witnessed one of the fastest growing economies in terms of GDP globally. Thanks to companies in this area, especially, Abu Dhabi National Oil Company (ADNOC), ADWEA, DEWA and other SOEs related to the travel and oil and gas sector. It is important to mention that Dubai is more diversified and has built a large private sector than Abu Dhabi Emirate (Anonymous, 2017). Nonetheless, the Abu Dhabi is major contributor to Oil GDP of UAE. In addition, it is important to mention that the SOEs rely heavily on Foreign workers from over 200 different national backgrounds. The challenge of working with different nationalities remains a major issue to multinational companies, SOEs and the UAE at large. Investigating the characteristics of project management process in SOEs would be of tremendous benefit to the UAE SOEs, multi-national businesses and other global enterprises at large. The aim of this study is to add to an enhanced understanding of project management and its impact on employee performance in terms of quality.

\section{Literature review}

Employee Performance (EP): Several assertions have been made regarding the association between project management and organizational performance. Studies in this area include (Barney, 1991; Newbert, 2007; Jugdev et al., 2007; Irefin, 2013) and others. These sources have usually associated project management with competitive advantage which in turn leads to performance in key areas of business management. The need to adopt project management approach to march performance effectiveness and efficiency is not new as Iretin (2013) emphasize that at least $50 \%$ of all work are usually carried out in the form of projects even though not all areas of initiation, planning, execution, monitoring and others are not strictly considered. Even though studies on effect of project on larger organizational performance has been observed, the employee performance as a dependent variable has not gained much attention.

Employee performance measurement and other work performance indicators have to some extent been considered as a measure of project management (Usmani, 2013). This is true despite a lack of clear literature establishing the association between project management and employee performance, considering employee performance is different in many ways from organizational performance. Nevertheless, project management assets used for the measurement of variables were debated as leading to performance at the organizational levels sually as a major contributor to these areas of project management assets from a strategic perspective. At the employee level, these have not been considered and remain exploratory.

Project management is measured with the help of four characteristics of project management assets acronym VRIO and mentioned by Jugdev and Mathur (2006) and Jugdev et al. (2007). Before attention is offered to how characteristics of project management may translate into competitive advantage or may affect employee performance, there is the need to focus on how project assets characteristics are associated with project assets. There is no doubt project management remains a source of competitive advantage for any organization. The source of competitiveness is established from two main sources in terms of resources tangible and intangible assets (Barney, 1991). Whereas tangible assets enhance the value and organizational support dimensions, intangible assets can fit all four areas of the key characteristics of project management success. Essentially, tangible assets are not rare and can only enhance value and organizational support. This study is interested in the capacity of project management asset characteristics to transform into specific competitive outcomes, building from tangible and intangible assets. The VRIO framework has been described as a strategic tool for analysing the internal environment of the firm (Barney and Hesterly, 2014), this framework can equally be used to manage the internal environment of the project and how tangible and intangible resources are challenged to meet project success criteria. Considering the three main areas of project success criteria (cost/value and time).

Project Management Assets (PMA): A firm is a collection of resources which can be tangible or intangible and include financial, human, organizational, physical, social and technological assets (Teece et al., 1997). A project has been defined, according to Atkinson (1999) as a system which does not remain constant but experiences continuous change, moving from one state or form to another. Jugdev and Mathur (2006) on the other hand also defined project as a group of people with task executed within a fixed time frame, directed at achieving a specific set of identifiable objectives. Akarakiri et al. (2012) also defined projects as a scheme that can be reasoned, analysed and considered to be an independent unit.

Previous empirical research reports on factors that create project management assets and relates them to the value, rarity, imitability and organization characteristics of the project management process achievement (Jugdev and Mathur, 2006; Mathur et al., 2007; 
Mathur et al., 2013; Mathur et al., 2014). This study takes a step further to link the project management assets characteristics $(\mathrm{V}, \mathrm{R}, \mathrm{I}$ and $\mathrm{O}$ ) to employee performance outcome (quality). Consequently, the following hypothesis are proposed:

- $\mathrm{H}_{1}$ : value has a positive effect on quality

- $\mathrm{H}_{2}$ : rarity has a positive effect on quality

- $\mathrm{H}_{3}$ : imitability has a positive effect on quality

- $\mathrm{H}_{4}$ : organization has a positive effect on quality

\section{MATERIALS AND METHODS}

Overview of the proposed research model: For this study, the hypothesized variables and their relationships in the model have been derived from the available literature of the models and theories that have been prescribed in the literature mentioned above. The proposed model can be seen in Fig. 1. While examining the proposed model, it can be seen that project management assets characteristics VIRO (Value, Rarity, Imitability and Organization) predicts employee performance (quality). These relationships are derived from (Barney and Hesterly, 2014; Jugdev and Mathur, 2006) whereas employee performance is taken from (Usmani, 2013). The proposed extended model examines the relationship between value, rarity, imitability and organization as antecedent variables that explain employee performance in terms of cost and time as an output variable among employees in State-Owned Enterprises SOE in the United Arab Emirates. The proposed model has eight hypothesis to test.

Development of instrument: A 23-item questionnaire was developed for this study and in line with existing literature in the project management assets field, a multi-item Likert scale was applied (Lee et al., 2009). Variables were measured using a Likert scale which recommended in the previous studies (Isaac et al., 2017a; Isaac et al., 2017b; Isaac et al., 2017a-e) with 7 being 'Strongly Agree' and 1 being 'Strongly Disagree'. Because respondents were Arabic-speakers, it was vital that the questionnaire be precisely translated from English to Arabic. Therefore, a back translation was performed, a procedure extensively applied to test the precision of the translation in a cross-cultural survey (Brislin, 1970). Validated instruments were adapted from related previous studies to measure the variables of this study as shown in Appendix A. With regard to item count for every construct, this study

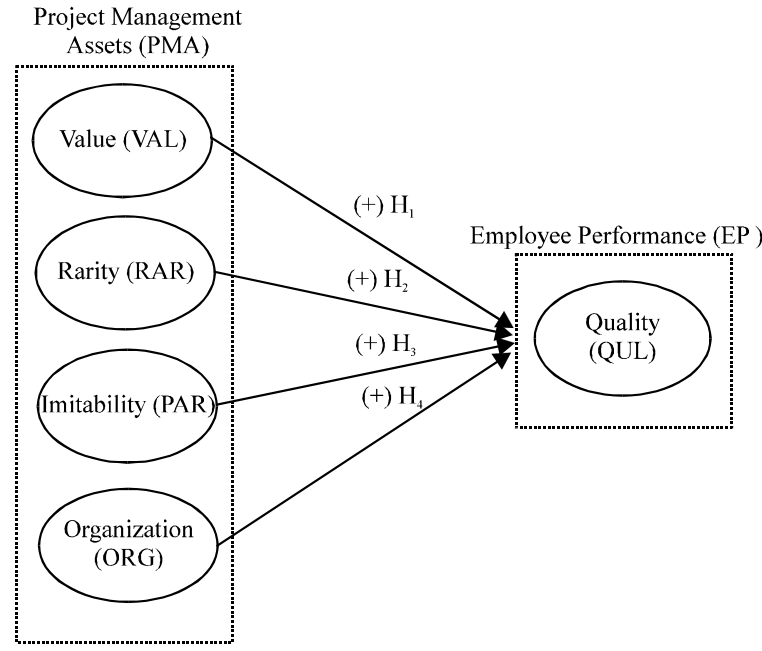

Fig. 1: The proposed model

followed the directions by Hayduk and Littvay (2012) who suggested using the few best items and that many items are rarely warranted because additional redundant items provide less research benefit.

Data collection: Data collection was conducted using a self-administered paper questionnaire which was delivered 'in-person' from December 2016 till February 2017 to employees. The employees were approached while in main facilities at Abu Dhabi Water and Electricity Authority (ADWEA), Dubai Electricity and Water Authority (DEWA), Sharjah Electricity and Water Authority (SEWA) and Federal Electricity and Water Authority (FEWA), they were given the questionnaire to be filled and left at the same place to be collected in the same day. A total of 900 questionnaires were distributed with 560 sets returned of which 541 responses were useful for the analysis. The final sample size was considered as adequate (Krejcie and Morgan, 1970; Tabachnick and Fidell, 2012). The $62 \%$ response rate is considered very good (Cable and Derue) and above average (Baruch and Holtom, 2008) by comparison with other studies found in the relevant literature. A total of 19 questionnaires were deleted of which 15 cases were removed due to missing data for more than $15 \%$ of the questions and 4 cases involving straight lining.

\section{RESULTS AND DISCUSSION}

Data analysis and results: Partial Least Squares (PLS) Structural Equation Modeling-Variance Based (SEM-VB) was utilized to examine the research model in this research 
Table 1: Mean, standard deviation, loading, Cronbach's alpha, CR and AVE

\begin{tabular}{|c|c|c|c|c|c|c|}
\hline Constructs/items & Loading $(>0.5)$ & $\mathrm{M}$ & SD & $\alpha(>0.7)$ & $\mathrm{CR}(>0.7)$ & $\operatorname{AVE}(>0.5)$ \\
\hline \multicolumn{7}{|l|}{ Value (VAL) } \\
\hline VAL1 & 0.878 & & & & & \\
\hline VAL2 & 0.808 & & & & & \\
\hline VAL3 & 0.809 & & & & & \\
\hline VAL4 & Deleted & 4.56 & 1.49 & 0.887 & 0.917 & 0.690 \\
\hline VAL5 & 0.790 & & & & & \\
\hline VAL6 & 0.865 & & & & & \\
\hline \multicolumn{7}{|l|}{ Rarity (RAR) } \\
\hline RAR1 & 0.885 & & & & & \\
\hline RAR2 & 0.812 & 4.60 & 1.47 & 0.796 & 0.880 & 0.711 \\
\hline RAR3 & 0.830 & & & & & \\
\hline \multicolumn{7}{|l|}{ Imitability (IMI) } \\
\hline IMI1 & 0.785 & & & & & \\
\hline IMI2 & 0.767 & & & & & \\
\hline IMI3 & 0.721 & 4.70 & 1.49 & 0.770 & 0.853 & 0.593 \\
\hline IMI4 & 0.804 & & & & & \\
\hline \multicolumn{7}{|c|}{ Organization (ORG) } \\
\hline ORG1 & Deleted & & & & & \\
\hline ORG2 & 0.864 & & & & & \\
\hline ORG3 & 0.723 & & & & & \\
\hline ORG4 & 0.712 & 4.62 & 1.45 & 0.831 & 0.882 & 0.601 \\
\hline ORG5 & 0.688 & & & & & \\
\hline ORG6 & Deleted & & & & & \\
\hline ORG7 & 0.868 & & & & & \\
\hline \multicolumn{7}{|l|}{ Quality (QUL) } \\
\hline QUL1 & 0.846 & & & & & \\
\hline QUL2 & 0.854 & & & & & \\
\hline QUL3 & 0.880 & 4.90 & 1.33 & 0.878 & 0.916 & 0.732 \\
\hline QULA & 0.843 & & & & & \\
\hline
\end{tabular}

by using the SmartPLS 3.0 Software (Ringle et al., 2015). A two-stage analytical method (Anderson and Gerbing, 1988; Hair et al., 2017) comprising measurement model assessment (validity and reliability) and structural model assessment (testing the hypothesized relationships) was used after conducting the descriptive analysis. This two-stage analytical method consisting of a measurement model and a structural model assessment is superior to a one-step assessment (Schumacker and Lomax, 2004; Hair et al., 2010). While the measurement model explains the measurement of each construct, the structural model defines the relationship between the variables in the structural model (Hair et al., 2017).

The use of PLS technique for both the measurement and the structural model in this research is due to its ability to perform simultaneous analysis, resulting in more precise assessments (Barclay et al., 1995). The main reasons for choosing SEM as a statistical method for this study is that SEM offers a simultaneous analysis which leads to more accurate estimates (Isaac et al., $2017 \mathrm{a}-\mathrm{e})$.

Descriptive analysis: Table 1 presents the mean and standard deviation of each variable in the current study.
The respondents were asked to indicate their opinion in relation to their online learning usage based on a 7-point scale ranging from 1 (strongly disagree) to 7 (strongly agree). Value recorded mean score of 4.56 out of 7.0 with a standard deviation of 1.49 indicating that the respondents agreed that project management has helped them be better, faster and cheaper in what they do increased their overall business performance, help them respond to industry threats and opportunities. Rarity recorded mean score of 4.60 out of 7.0 with a standard deviation of 1.47 , indicating that the respondents agreed that it will be difficult to copy practice of project management in their company. Imitability recorded mean score of 4.70 out of 7.0 with a standard deviation of 1.49 , indicating that the respondents agreed that many organizations in their industry do not practice project management the way they do and how they practice project management makes the practice unique to their 7 organization. Organization recorded mean score of 4.60 out of 7.0 with a standard deviation of 1.45 indicating that the respondents agreed that project management is important to the mission of their organization, they benchmark regularly to assess best practices in project management that could improve their practices and their 
Table 2: Results of discriminant validity by the cross loading

\begin{tabular}{|c|c|c|c|c|c|}
\hline Factors & VAL & RAR & IMI & ORG & QUL \\
\hline VAL1 & 0.878 & 0.663 & 0.583 & 0.617 & 0.526 \\
\hline VAL2 & 0.808 & 0.572 & 0.626 & 0.580 & 0.555 \\
\hline VAL3 & 0.809 & 0.619 & 0.640 & 0.589 & 0.623 \\
\hline VAL5 & 0.790 & 0.499 & 0.665 & 0.652 & 0.558 \\
\hline VAL6 & 0.865 & 0.663 & 0.600 & 0.610 & 0.509 \\
\hline RAR1 & 0.672 & 0.885 & 0.593 & 0.625 & 0.532 \\
\hline RAR2 & 0.601 & 0.812 & 0.637 & 0.570 & 0.573 \\
\hline RAR3 & 0.569 & 0.830 & 0.628 & 0.562 & 0.631 \\
\hline IMI1 & 0.619 & 0.604 & 0.785 & 0.591 & 0.560 \\
\hline IMI2 & 0.559 & 0.618 & 0.767 & 0.540 & 0.583 \\
\hline IMI3 & 0.466 & 0.471 & 0.721 & 0.460 & 0.535 \\
\hline IMI4 & 0.666 & 0.574 & 0.804 & 0.742 & 0.618 \\
\hline ORG2 & 0.598 & 0.494 & 0.660 & 0.864 & 0.569 \\
\hline ORG3 & 0.625 & 0.637 & 0.511 & 0.723 & 0.445 \\
\hline ORG4 & 0.544 & 0.531 & 0.550 & 0.712 & 0.476 \\
\hline ORG5 & 0.505 & 0.568 & 0.564 & 0.688 & 0.545 \\
\hline ORG7 & 0.587 & 0.485 & 0.652 & 0.868 & 0.564 \\
\hline QUL1 & 0.619 & 0.610 & 0.626 & 0.576 & 0.846 \\
\hline QUL2 & 0.541 & 0.601 & 0.654 & 0.575 & 0.854 \\
\hline QUL3 & 0.554 & 0.602 & 0.662 & 0.517 & 0.880 \\
\hline QUL4 & 0.588 & 0.552 & 0.615 & 0.647 & 0.843 \\
\hline
\end{tabular}

Bold values the indicator's outer loadings on a construct exceeded all its cross-loadings with other constructs. VAL: Value, RAR: Rarity, IMI: Imitability, ORG: Organization, QUL: Quality

project management practice has improved year by year. Quality recorded mean score of 4.90 out of 7.0 with a standard deviation of 1.33, indicating that the respondents agreed that employees are able to execute activities, according to design, employee performance is error-free and employees have stakeholder's best interests at heart.

Measurement model assessment: Construct reliability and validity (consisting of convergent and discriminant validity) were utilized to test the measurement model. The individual Cronbach's alpha coefficients were examined to ascertain the reliability of each core variable in the measurement model (construct reliability). The values of all the individual Cronbach's alpha coefficients in this study were between $0.797-0.887$ which exceeded the suggested value of 0.7 (Kannan and Tan, 2005; Nunnally and Bernstein). Furthermore, for testing construct reliability, the values of all the Composite Reliability (CR) were between 0.853- 0.917 which exceeded 0.7 (Werts et al., 1974; Kline, 2010; Gefen et al., 2000). Therefore, as illustrated in Table 1, construct reliability has been satisfied as Cronbach's alpha and CR were relatively error-free for all the constructs.

Assessment of indicator reliability was done by using factor loadings. When the associated indicators have much in common, this is captured in the construct and indicated by high loadings on the construct (Hair et al., 2017). According to Hair et al. (2010), values exceeding 0.50 indicate significant factor loadings. Table 1 shows that all items in this study had factor loadings higher than the recommended value of 0.5 , except for items VAL4,
ORG1 and ORG6 which had low loadings. Therefore, they were removed from the scale. All other items in the model satisfied all the loading requirements.

Average Variance Extracted (AVE) was used in this study to assess convergent validity which shows the degree that a measure correlates positively with alternative measures of the same construct. The values of all AVE were between 0.593-0.732 which exceeded the recommended value of 0.50 (Hair et al., 2010). Therefore, all constructs have fulfilled the convergent validity satisfactorily as illustrated in Table 1 .

The extent that items differentiate among constructs or measure distinct concepts is shown by discriminant validity. Cross-loadings, Fornell-Larcker and Heterotrait-Monotrait ratio (HTMT) were used to assess the discriminant validity of the measurement model. Usually, cross-loadings are used as the first step in testing discriminant validity of the indicators (Hair et al., 2017). In this study, the indicator's outer loadings on a construct exceeded all its cross-loadings with other constructs and hence, the cross loading criterion had satisfied the requirements (Table 2).

Table 3 displays the results for discriminant validity by using the Fornell-Larcker criterion. It was found that the square root of the AVEs on the diagonals (shown in bold) are greater than the correlations between constructs (corresponding row and column values), indicating strong correlation between the constructs and their respective indicators as compared to the other constructs in the model (Fornell and Larcker, 1981; Chin, 1998a, b). According to Hair et al. (2017), this indicates a good discriminant validity. Furthermore, the exogenous 
Table 3: Results of discriminant validity by Fornell-Larcker criterion

\begin{tabular}{llllll}
\hline & 1 & 2 & 3 & 4 & 5 \\
Factors & IMI & ORG & QUL & RAR & \\
IMI & $\mathbf{0 . 7 7 0}$ & & & & \\
ORG & 0.764 & $\mathbf{0 . 7 7 5}$ & $\mathbf{0 . 8 5 6}$ & $\mathbf{0 . 8 4 3}$ & \\
QUL & 0.747 & 0.676 & 0.691 & 0.727 & \\
RAR & 0.738 & 0.694 & 0.672 & $\mathbf{0 . 8 3 1}$ \\
VAL & 0.753 & 0.735 &
\end{tabular}

Bold values (Diagonals) represent the square root of the average variance extracted while the other entries represent the correlations. VAL: Value, RAR: Rarity, IMI: Imitability, ORG: Organization, QUL: Quality

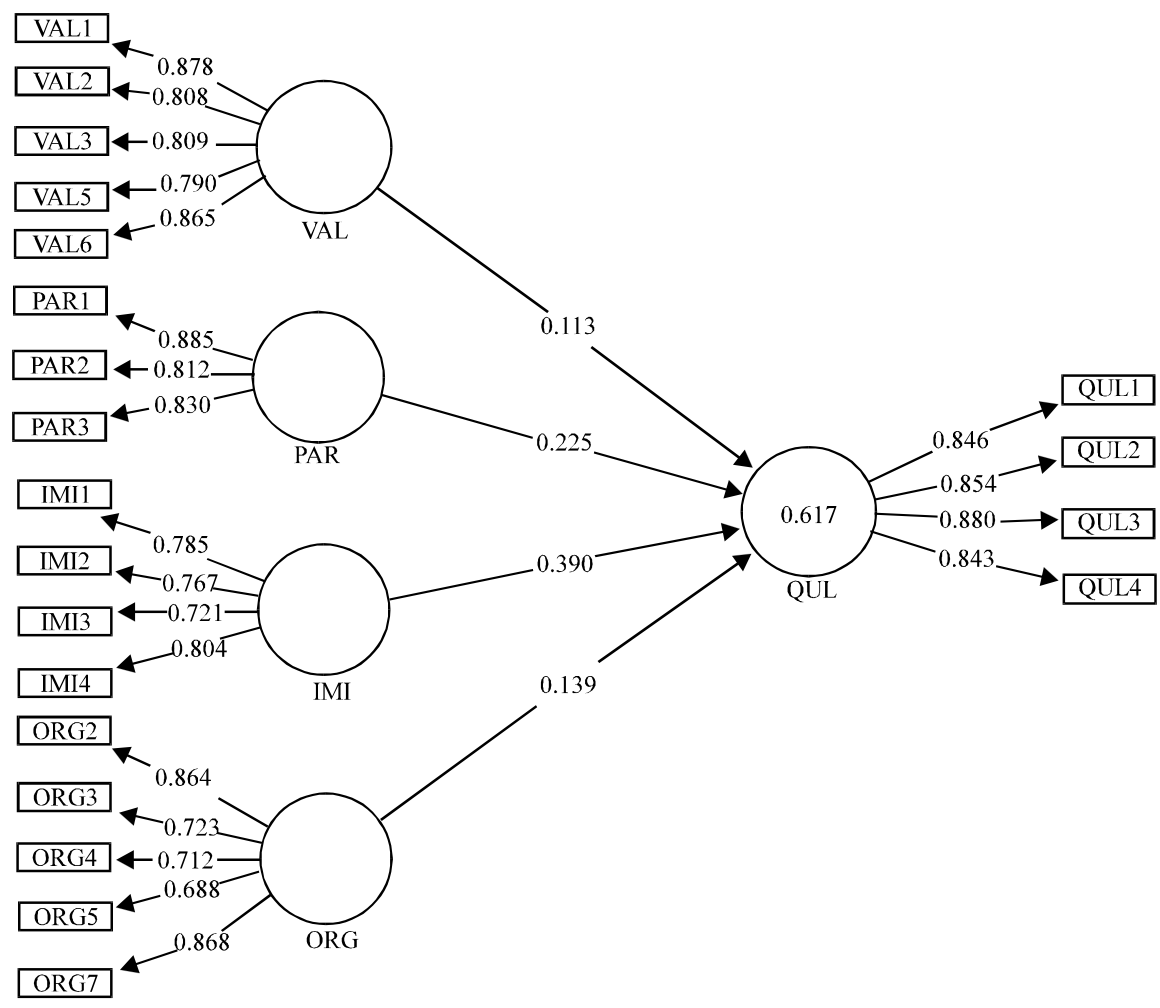

Fig. 2: PLS algorithm results; VAL: Value, RAR, Rarity, IMI: Imitability, ORG: organization, QUL: Quality

constructs have a correlation of $<0.85$ (Awang, 2014). Therefore, all constructs had their discriminant validity fulfilled satisfactorily.

Structural model assessment: The structural model can be tested by computing beta $(\beta), \mathrm{R}^{2}$ and the corresponding t-values via. a bootstrapping procedure with a resample of 5,000 (Hair et al., 2017). They also suggested looking at the effect sizes $\left(\mathrm{f}^{2}\right)$ and the predictive relevance $\left(\mathrm{Q}^{2}\right)$. While p-value ascertains the existence of the effect, the effect size is not shown (Sullivan and Feinn, 2012).

Hypothesis tests: Figure 2 and Table 4 depict the structural model assessment, showing the results of the hypothesis tests with 4 out of the 4 hypothesis are supported. Value, rarity, imitability and organization significantly predict quality. Hence, $\mathrm{H}_{1}, \mathrm{H}_{2}, \mathrm{H}_{3}$ and $\mathrm{H}_{4}$ are accepted with $(\beta=0.113, \mathrm{t}=2.134 \mathrm{p}<0.05),(\beta=0.225$, $\mathrm{t}=5.509, \mathrm{p}<0.001),(\beta=0.390 \mathrm{t}=6.983 \mathrm{p}<0.001)$ and $(\beta=0.139, t=2.608 p<0.01)$, respectively.

The strength of the relationship between exogenous and endogenous constructs are measured by the standardised path coefficients which in this case show that the direct effects of imitability on quality is much stronger than the influence of other variables. About $62 \%$ of the variance in cost is explained by value, rarity, imitability and organization. The values of $\mathrm{R}^{2}$ have an acceptable level of explanatory power, indicating a substantial model (Cohen, 1988; Chin, 1998a, b).

Effect sizes $\left(\mathrm{f}^{2}\right)$ was examined in this research. According to Gefen and Ringdon (2011), the effect size $\mathrm{f}^{2}$ 
Table 4: Structural path analysis result

\begin{tabular}{|c|c|c|c|c|c|c|c|c|c|c|}
\hline Hypothesis & Relationship & Std Beta & SE & $\mathrm{t}$-value & $p$-value & Decision & $\mathrm{R}^{2}$ & $\mathrm{f}^{2}$ & $\mathrm{Q}^{2}$ & VIF \\
\hline $\mathrm{H}_{1}$ & $\mathrm{VAL} \rightarrow \mathrm{QUL}$ & 0.113 & 0.053 & 2.134 & 0.017 & Supported & 0.62 & 0.011 & 0.413 & 3.293 \\
\hline $\mathrm{H}_{2}$ & $\mathrm{RAR} \rightarrow \mathrm{QUL}$ & 0.225 & 0.041 & 5.509 & 0.000 & Supported & & 0.050 & & 2.891 \\
\hline $\mathrm{H}_{3}$ & $\mathrm{IMI} \rightarrow \mathrm{QUL}$ & 0.390 & 0.056 & 6.983 & 0.000 & Supported & & 0.120 & & 2.664 \\
\hline$\underline{\mathrm{H}_{4}}$ & ORG $\rightarrow$ OUL & 0.139 & 0.053 & 2.608 & 0.005 & Supported & & 0.017 & & 2.978 \\
\hline
\end{tabular}

VAL: Value, RAR: Rarity, IMI: Imitability, ORG: Organization, QUL: Quality

Table 5: IPMA for quality

\begin{tabular}{lcc}
\hline Latent constructs & Total effect of the construct quality (Importance) & Index values (Performance) \\
\hline Value (VAL) & 0.113 & 60.19 \\
Rarity (RAR) & 0.225 & 59.37 \\
Imitability (IMI) & 0.390 & 61.77 \\
Organization (ORG) & 0.139 & 60.15 \\
\hline
\end{tabular}

ascertains the impact of an exogenous latent construct (whether substantial, moderate or weak) on an endogenous latent construct. It is suggested that the change in $\mathrm{R}^{2}$ value is assessed (Hair et al., 2017). The $\mathrm{f}^{2}$ value of 0.35 indicates large effects, 0.15 indicates medium effects and 0.02 indicates small effects (Cohen, 1988). Table 4 displays the $\mathrm{f}^{2}$ results, indicating four medium effect sizes relationships and one small effect size relationship.

In assessing the predictive relevance of the proposed research model, this study had applied the blindfolding procedure. This procedure should be employed on endogenous constructs with a reflective measurement only (Hair et al., 2017). According to Fornell and Cha (1994) and Hair et al. (2017), a particular endogenous construct of the proposed model has predictive relevance if the value of $Q^{2}$ exceeded 0 . In this study, all $Q^{2}$ values were $>0$ and hence, it can be concluded that the proposed model has an adequate predictive relevance (Table 4). Relative measure of predictive relevance is indicated by $Q^{2}$ values of 0.35 for large, 0.15 for medium and 0.02 for small. All exogenous constructs in this study were found to have large predictive relevance.

According to O'brien (2007), the existence of multicollinearity poses a problem as it indicates overlapping of the variance that the exogenous constructs explain in the endogenous construct. Therefore, it cannot justify each variance in the endogenous variable. Variance Inflation Factor (VIF) is commonly used as a measurement of the degree of multicollinearity (O'Brien, 2007). A value exceeding 10 for the largest VIF indicates a problem (Bowerman and O'connell, 1990; Myers, 1990). Meanwhile, Hair et al. (2017) suggested that a value exceeding 5 for the largest VIF indicates a multicollinearity problem. The VIF values in this study are between $2.664-2.978$ (i.e. $<5$ ) and hence, there is no significant multicollinearity issue among the exogenous constructs. In other words, there is no overlapping of the variance that the exogenous constructs explained in the endogenous construct.

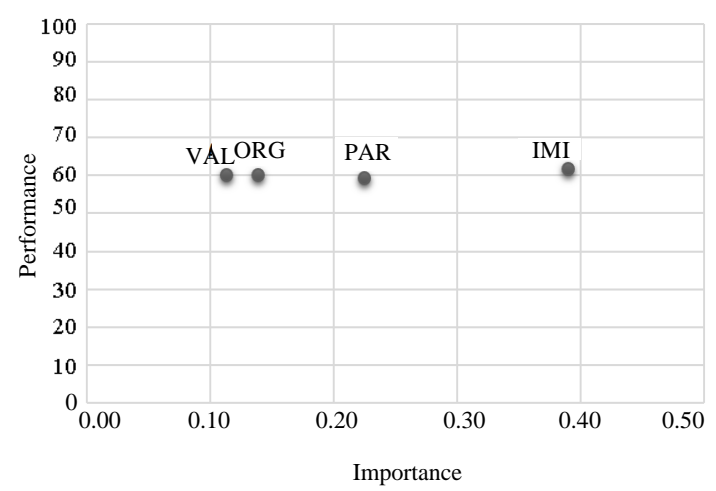

Fig. 3: IPMA (Priority Map) for quality VAL: Value, RAR; Rarity, IMI; Imitability, ORG; Organization

Importance-Performance Map Analysis (IPMA): Importance-performance matrix analysis (IPMA) was employed as a post-hoc PLS procedure in this study with the actual usage of online learning used as the outcome construct. According to Hair et al. (2017), the IPMA provides an estimation of the total effects corresponding to the importance of predecessor constructs in affecting the target construct (actual usage) the average latent variable scores correspond to their performance whereas the index value's (performance scores) calculation was achieved by rescaling the scores of the latent constructs to within a range from 0 (lowest performance) to 100 (highest performance). IPMA enhances the results of PLS analysis (Ringle and Sarstedt, 2016) because it gives attention to the latent construct's average value as well as their indicators (the performance dimension), in addition to performing the path coefficients analysis (the importance dimension). The results for total effects (importance) and index values (performance) of the IPMA of the outcome construct quality is displayed in Table 5 .

As shown in Fig. 3, this study plotted the total effects scores and index values out in a priority map, it can be observed that imitability is very important factor in determining the quality due to its relatively higher importance values compared to other constructs in the 
proposed model. Rarity and organization are the second important factors in determining the quality. While the weak factor is value.

Nevertheless, the performance of this significant factor (rarity) lagged behind the value. According to Hair et al. (2017), the goal of IPMA is to identify predecessors that have a relatively high importance for the target construct (i.e., those that have a strong total effect) but also a relatively low performance (i.e., low average latent variable scores), the aspects underlying these constructs represent potential areas of improvement that may receive high attention.

Although, variables such as value scored relatively intermediate in performance, it has small relevance in influence quality. In sum in order to improve the quality, the managerial activities should focus on enhancing the performance of imitability.

Based on the proposed model, this study improves the understanding of the role played by project management assets in terms of employee performance in State-Owned Enterprises SOE in the United Arab Emirates and highlights relevant implications and suggestions for management and policy makers. The discussions are further detailed in the following.

The study found that value positively affect quality. This is explained by the fact that the more project management asset is enhancing the overall performance and profitability, the more the employees are able to work according to specifications of job description and to execute activities according to design with an error-free performance and have stakeholders best interests at heart. These results are in line with previous studies in the project management assets field (Aubry et al., 2007; Patanakul et al., 2010). Likewise, rarity was found to positively affect quality. This is explained by the fact that the more project management asset is considered rare where competitors do not possess it, the more the employees are able to work according to specifications of job description and to execute activities according to design with an error-free performance and have stakeholders best interests at heart. These results are in line with previous studies in the project management assets field (Besner and Hobbs, 2004; Mathur et al., 2013; Fortune et al., 2011; Mathur et al., 2007).

Additionally, imitability was found to positively affect quality. This is explained by the fact that the more project management asset is unique and hard to imitate and is specific to this business, The more the employees are able to work, according to specifications of job description and to execute activities, according to design with an error-free performance and have stakeholders best interests at heart. These results are in line with previous studies in the project management assets field (Aghazadeh, 2015; Karpen et al., 2015). Finally, organizational aspects was found to positively affect quality. This is explained by the fact that the more project management asset is supported by an a formal project management role which is included in the mission of the enterprise. The more the employees are able to work, according to specifications of job description and to execute activities, according to design with an error-free performance and have stakeholders best interests at heart. These results are in line with previous studies in the project management assets field (Aghazadeh, 2015; Mathur et al., 2013).

According to the importance-performance map analysis (Fig. 3), imitability is the highest antecedent in terms of importance and performance within the examined model that can make a significant effect on the quality of employee performance followed by rarity, organization and value. Therefore, top management should give priority to imitability of its project management assets to enhance the quality of its employee performance in state-owned enterprises.

Implication for practice: The United Arab Emirates has a long-term strategy which aimed to develop a reliable and efficient administration to its State-Owned Enterprises SOE by improving the management of its assets to deliver lasting benefits for all its citizens and gain recognition around the world. The implications of this study could provide significant benefits to managerial boards and policy makers at these enterprises on how to utilize its strategic assets in a way that enhance the performance of its employees. A number of practical implications were found such as understanding the factors that influence the quality of employee performance factor which leads to improving professional practice, professional development and quality of work. Significantly, the implications of using the proposed model provide an understanding of the relationships of key determinants to employee performance which leads to improving productivity and effectiveness.

This research also contributes to practice by focusing managerial attention to project management assets as sources of competitive advantage. It highlights that project management assets are not only a set of tools and techniques to achieve a project objectives 
but also include intangible elements that are embedded in the routines and relationships of an organization.

Moreover, this research could build on an increased awareness among state-owned enterprises in the UAE of the importance of focusing on factors which are additional to the VRIO-attributes when analyzing potential strategic resources (Andersen, 2011), besides representing a useful instrument to assist top management to come out with a list of potential competitive advantages of the available sources (Lin et al., 2012). In addition to improve resource specifying and selection by acknowledging, the positive-only tenor of VRIO materials (Knott, 2015).

\section{CONCLUSION}

The United Arab Emirates has always been a pioneer in wide range of aspects among its neighbours and around the world (World Bank, 2017; Schwab and Sala-i-Martin, 2014). However, it is striving to enhance its employee performance in terms of cost, time and quality (Global Innovation Index, 2016), the findings of this study could be considered as one of the initiatives to serve on that direction. The main objective of this study is to determine factors that affect employee performance within state-owned enterprises in the United Arab Emirates. Despite various constraints to the study, the results have been encouraging as it has managed to throw some lights on a new perspective. This study proposed a model which include project management characteristics namely, value, rarity, imitability and organization as independent variables and employee performance in terms quality as the dependent variable. The results revealed that the four independent variables significantly explain $61 \%$ of quality. The implications of this study from the perspective of research and practitioners have been deliberated, limitations have been noted and some directions for future research have been suggested.

\section{IMPLICATIONS}

This study has applied the resource based value of the State-owned Enterprises SOE in the United Arab Emirates to examine project management capabilities as a source of competitive advantage and its effect on the performance of employees. This research can be seen as an attempt to contribute to the understanding of the characteristics of project management assets that lead to a firm's competitive advantage and thus enhanced employees performance (Mathur et al., 2013). This concept has significant value for researchers interested in project management. It is differentiated from prior research that has explored the link between assets and the achievement of the VRIO characteristics from the process by extending the conceptual model to link VRIO characteristic to employee performance. It can be distinguished from previous models in proposing that organizational culture as a moderating variable that is required for assets that are valuable, rare and inimitable to contribute to project management outcomes in terms of employee performance. This research offers empirical support to the theoretical relevance of valuable, rare, imperfectly imitable and organizational conditions of resources and capabilities that permit efficient and effective value creation. (Karpen et al., 2015).

\section{SUGGESTIONS}

In addition to the limited scope of the study and limitations with regard to sample size, response rate and self-report bias, it is believed that this study has a valid and reliable instrument to test relationships between the factors and examine hypothesis that the valuable, rare, inimitable and organization characteristics of project management assets will predict employee performance outcome specifically quality. Moreover, cross-sectional was used as the research design of this current research whereby all the variables incorporated in the hypothesized model were evaluated at a single point in time (Aldholay et al., 2018a-c; Mutahar et al., 2018). According to Wulf (1999), no definite conclusions can be drawn from such an approach, specifically regarding the causality of relationships among variables. As for future work, Hofstede et al., mentioned that UAE is among the countries that have a high power distance where people accept hierarchical order and centralization is popular. Organizational structure is seen as a crucial to better employee performance. Based on that future researchers could extend the proposed model in this study by adding the role of organizational structure.

\section{ACKNOWLEDGEMENT}

This research was supported by Lincoln University College (LUC). We thank also State-Owned Enterprises (SOEs) in the UAE who provided insight and expertise that greatly assisted the research. 
Appendix A: Instrument for varibles

\begin{tabular}{|c|c|c|}
\hline$\underline{\text { Varible }}$ & Measure & Source \\
\hline \multicolumn{3}{|c|}{ Value (VAL) } \\
\hline VAL1: & Project management has helped us be better, faster and cheaper in what we do & \\
\hline VAL2: & Project management has increased our profitability & \\
\hline VAL3: & Project management has increased our overall business performance & \\
\hline VALA: & $\begin{array}{l}\text { Managing things in the form of projects at my organization help us } \\
\text { respond to industry threats and opportunities }\end{array}$ & \\
\hline VAL5: & We used project management to provide better products and services & \\
\hline VAL6: & Project management is a source of competitive dvantage to my company & \\
\hline \multicolumn{3}{|c|}{ Rarity (RAR) } \\
\hline RAR1: & $\begin{array}{l}\text { We made rare decisions in the past which helped us achieve success through } \\
\text { project management }\end{array}$ & \\
\hline RAR2: & Organizations who do not use project management the way we do have a cost disadvantage & \\
\hline RAR3: & It will be difficult to copy practice of project management in my company & \\
\hline \multicolumn{3}{|c|}{ Imitability } \\
\hline (IMI) & Many organizations in our industry do not practice project management the way we do & \\
\hline IMI1: & How we practice project management makes the practice unique to my organization & \\
\hline ІМП2: & Even if $1 / 3$ of those people that practice project management in my company & (Jugdev and \\
\hline IMI3: & lest tomorrow project management will still not change & Mathur, 2006) \\
\hline IMI4: & Relative to our competitors, project management in my company is unique & \\
\hline \multicolumn{3}{|c|}{ Organization (ORG) } \\
\hline ORG1: & $\begin{array}{l}\text { We are well organized to practice project management at my organization } \\
\text { with policies, procedures and routines }\end{array}$ & \\
\hline ORG2: & Project management is important to the mission of our organization & \\
\hline ORG3: & Project management is an organization-wide initiative & \\
\hline ORG4: & Executive at my organization have formal project management roles & \\
\hline ORG5: & Executive at my organization are effective at their project management roles & \\
\hline ORG6: & $\begin{array}{l}\text { We benchmark regularly to assess best practices in project management that } \\
\text { could improve our practices }\end{array}$ & \\
\hline ORG7: & Our project management practice has improved year by year & \\
\hline \multicolumn{3}{|c|}{ 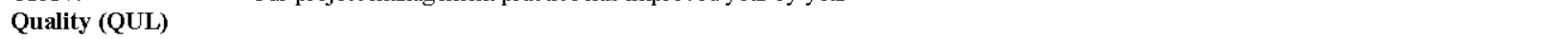 } \\
\hline QUL1: & $\begin{array}{l}\text { Employ ees within this organization are able to work, according to } \\
\text { specifications of job description. Employees are able to execute activities, } \\
\text { according to design }\end{array}$ & \\
\hline QUL2: & Employee performance are error-free & (Comu et al., 2011; \\
\hline QUL3: & Employees have stakeholder's best interests at heart & $\begin{array}{l}\text { Kagaari et al., 2010; } \\
\text { Zhu and Huang, 2007) }\end{array}$ \\
\hline
\end{tabular}

\section{REFERENCES}

Aghazadeh, H., 2015. Strategic marketing management: Achieving superior business performance through intelligent marketing strategy. Procedia Soc. Behav. Sci., 207: 125-134.

Akarakiri, J.B., I.A. Irefin and O.I. Olateju, 2012. An evaluation of the effects of project management techniques on the performance of the textile industry in South-Western Nigeria. Trans. J. Sci. Technol., 2: 28-49.

Aldholay, A.H., O. Isaac, Z. Abdullah and T. Ramayah, 2018 c. The role of transformational leadership as a mediating variable in DeLone and McLean information system success model: The context of online learning usage in Yemen. Telematics Inf., 35: 1421-1437.

Aldholay, A.H., O. Isaac, Z. Abdullah, I. Alrajawy and M. Nusari, 2018a. The role of compatibility as a moderating variable in the information system success model: The context of online learning usage. Intl. J. Manage. Hum. Sci., 2: 9-15.
Aldholay, A.H., Z. Abdullah, T. Ramayah, O. Isaac and A.M. Mutahar, 2018b. Online learning usage and performance among students within public universities in Yemen. Intl. J. Serv. Stand., 12: 163-179.

Andersen, J., 2011. Strategic resources and firm performance. Manage. Decis., 49: 87-98.

Anderson, J.C. and D.W. Gerbing, 1988. Structural equation modeling in practice: $\mathrm{A}$ review and recommended two-step approach. Psychol. Bull., 103: 411-423.

Anonymous, 2017. Doing business in the UAE. PricewaterhouseCoopers, London, England, UK. https://www.pwc.de/de/internationale-maerkte/asse ts/doing-business-in-the-uae.pdf

Atkinson, R., 1999. Project management: Cost, time and quality, two best guesses and a phenomenon, its time to accept other success criteria. Int. J. Project Manage., 17: 337-342.

Aubry, M., B. Hobbs and D. Thuillier, 2007. A new framework for understanding organisational project management through the PMO. Int. J. Project Manage., 25: 328-336. 
Awang, Z., 2014. Structural Equation Modeling Using AMOS. Penerbit Universiti Teknologi MARA, Shah Alam, Malaysia..

Barclay, D., C. Higgins and R. Thompson, 1995. The Partial Least Squares (PLS) approach to causal modeling: Personal computer adoption and use as an illustration. Technol. Stud., 2: 285-309.

Barney, J.B. and W.S. Hesterly, 2014. Strategic Management and Competitive Advantage: Concepts and Cases. 5th Edn., Pearson, London, UK., ISBN:9780134099002, Pages: 400.

Barney, J.B., 1991. Firm resources and sustained competitive advantage. J. Manage., 17: 99-120.

Baruch, Y. and B.C. Holtom, 2008. Survey response rate levels and trends in organizational research. Hum. Relat., 61: 1139-1160.

Besner, C. and B. Hobbs, 2004. An empirical investigation of project management practice: In reality, which tools do practitioners use. Innovations Project manage. Res., 1: 337-351.

Bowerman, B.L. and R.T. O'connell, 1990. Linear Statistical Models: An Applied Approach. 2nd Edn., Duxbury Press, New York, USA., ISBN:9780534229856, Pages: 1024.

Brislin, R.W., 1970. Back-translation for cross-cultural research. J. Cross Cultural Psychol., 1: 185-216.

Chin, W., 1998a. The Partial Least Squares Approach for Structural Equation Modeling. In: Modern Methods for Business Research, Marcoulides, G.A. (Ed.). Lawrence Erlbaum Associates, New Jersey, pp: 295-336.

Chin, W.W., 1998b. Commentary: Issues and opinion on structural equation modeling. MIS Q., 22: 7-16.

Cohen, J., 1988. Statistical Power Analysis for the Behavioral Sciences. 2nd Edn., Lawrence Erlbaum, Hillsdale, New Jersey, USA., ISBN: 0-8058-6283-5, Pages: 128.

Comu, S., H.I. Unsal and J.E. Taylor, 2010. Dual impact of cultural and linguistic diversity on project network performance. J. Manage. Eng., 27: 179-187.

Fornell, C. and D.F. Larcker, 1981. Evaluating structural equation models with unobservable variables and measurement error. J. Market. Res., 18: 39-50.

Fortune, J., D. White, K. Jugdev and D. Walker, 2011. Looking again at current practice in project management. Intl. J. Managing Projects Bus., 4: 553-572.

Gefen, D., D. Straub and M.C. Boudrea, 2000. Structural equation modeling techniques and regression: Guidelines for research practice. Commun. Assoc. Inform. Syst., 7: 1-79.
Global Innovation Index, 2016. Government institutions effectiveness: Yemen versus Arab countries: Rank among 143 countries. Cornell University, INSEAD, The World Intellectual Property Organization (WIPO), Geneva, Switzerland.

Hair, Jr., J.F., G.T.M. Hult, C.M. Ringle and M. Sarstedt, 2017. A Primer on Partial Least Squares Structural Equation Modeling (PLS-SEM). 2nd Edn., Sage Publisher, Thousand Oaks, California.

Hair, Jr., J.F., W.C. Black, B.J. Babin and R.E. Anderson, 2010. Multivariate Data Analysis. 7th Edn., Prentice Hall, Upper Saddle River, NJ., ISBN-13: 9780138132637, Pages: 785.

Hayduk, L.A. and L. Littvay, 2012. Should researchers use single indicators, best indicators, or multiple indicators in structural equation models?. BMC. Med. Res. Method., 12: 1-17.

Irefin, I.A., 2013. Effects of project management on the performance of a construction firm in Nigeria. Am. Intl. J. Contemp. Res., 3: 54-58.

Isaac, O., Y. Masoud, S. Samad and Z. Abdullah, 2016. The mediating effect of strategic implementation between strategy formulation and organizational performance within government institutions in Yemen. Res. J. Appl. Sci., 11: 1002-1013.

Isaac, O., Z. Abdullah, T. Ramayah and A.M. Mutahar, 2017a. Examining the relationship between overall quality, user satisfaction and internet usage: An integrated individual, technological, organizational and social perspective. Asian J. Inf. Technol., 16: 100-124.

Isaac, O., Z. Abdullah, T. Ramayah and A.M. Mutahar, $2017 \mathrm{~b}$. Internet usage and net benefit among employees within government institutions in Yemen: An extension of Delone and Mclean Information Systems Success Model (DMISM) with task-technology fit. Intl. J. Soft Comput., 12: 178-198.

Isaac, O., Z. Abdullah, T. Ramayah and A.M. Mutahar, $2017 \mathrm{c}$. Internet usage within government institutions in Yemen: An extended Technology Acceptance Model (TAM) with internet self-efficacy and performance impact. Sci. Intl., 29: 737-747.

Isaac, O., Z. Abdullah, T. Ramayah and A.M. Mutahar, 2017 d. Internet usage, user satisfaction, task-technology fit and performance impact among public sector employees in Yemen. Intl. J. Inf. Learn. Technol., 34: 210-241.

Isaac, O., Z. Abdullah, T. Ramayah, A.M. Mutahar and I. Alrajawy, 2017e. Towards a better understanding of internet technology usage by Yemeni employees in the public sector: An extension of the Task-Technology Fit (TTF) model. Res. J. Appl. Sci., 12: $205-223$. 
Jugdev, K. and G. Mathur, 2006. Project management elements as strategic assets: Preliminary findings. Manage. Res. News, 29: 604-617.

Jugdev, K., G. Mathur and T.S. Fung, 2007. Project management assets and their relationship with the project management capability of the firm. Int. J. Project Manage., 25: 560-568.

Kagaari, J., J.C. Munene and M.J. Ntayi, 2010. Performance management practices, employee attitudes and managed performance. Int. J. Educ. Manage., 24: 507-530.

Kannan, V.R. and K.C. Tan, 2005. Just in time, total quality management and supply chain management: Understanding their linkages and impact on business performance. Omega Intl. J. Manage. Sci., 33: $153-162$.

Karpen, I.O., L.L. Bove, B.A. Lukas and M.J. Zyphur, 2015. Service-dominant orientation: Measurement and impact on performance outcomes. J. Retailing, 91: 89-108.

Kline, R.B., 2010. Principles and Practice of Structural Equation Modeling. 3rd Edn., The Guilford Press, New York, USA., ISBN-13: 9781606238769 , Pages: 427.

Knott, P.J., 2015. Does VRIO help managers evaluate a firm's resources?. Manage. Decis., 53: 1806-1822.

Krejcie, R.V. and D.W. Morgan, 1970. Determining sample size for research activities. Educ. Psychol. Meas., 30: 607-610.

Lee, B.C., J.O. Yoon and I. Lee, 2009. Learners' acceptance of E-learning in South Korea: Theories and results. Comput. Educ., 53: 1320-1329.

Lin, C., H.L. Tsai, Y.J. Wu and M. Kiang, 2012. A fuzzy quantitative VRIO-based framework for evaluating organizational activities. Manage. Decis., 50: 1396-1411.

Mathur, G., K. Jugdev and T.S. Fung, 2007. Intangible project management assets as determinants of competitive advantage. Manage. Res. News, 30: 460-475.

Mathur, G., K. Jugdev and T.S. Fung, 2013. Project management assets and project management performance outcomes: Exploratory factor analysis. Manage. Res. Rev., 36: 112-135.

Mathur, G., K. Jugdev and T.S. Fung, 2014. The relationship between project management process characteristics and performance outcomes. Manage. Res. Rev., 37: 990-1015.
Mutahar, A.M., N.M. Daud, T. Ramayah, O. Isaac and A.H. Aldholay, 2018. The effect of awareness and perceived risk on the Technology Acceptance Model (TAM): Mobile banking in Yemen. Intl. J. Serv. Stand., 12: 180-204.

Myers, R.H., 1990. Classical and Modern Regression with Applications. 2nd Edn., Duxbury, Washington.

Newbert, S.L., 2007. Empirical research on the resource-based view of the firm: An assessment and suggestions for future research. Strategic Manage. J., 28: 121-146.

O'Brien, R.M., 2007. A caution regarding rules of thumb for variance inflation factors. Qual. Quantity, 41: 673-690.

Patanakul, P., B. Iewwongcharoen and D. Milosevic, 2010. An empirical study on the use of project management tools and techniques across project life-cycle and their impact on project success. J. Gen. Manage., 35: 41-65.

Ringle, C.M. and M. Sarstedt, 2016. Gain more insight from your PLS-SEM results: The importance-performance map analysis. Ind. Manage. Data Syst., 116: 1865-1886.

Ringle, C.M., S. Wende and J.M. Becker, 2015. SmartPLS 3. SmartPLS GmbH, Bonningstedt, Germany.

Schumacker, R.E. and R.G. Lomax, 2004. A Beginner's Guide to Structural Equation Modeling. 2nd Edn., Lawrence Erlbaum Associates, New Jersey, USA., ISBN:0-8058-4017-6,

Schwab, K. and X. Sala-i-Martin, 2014. The Global Competitiveness Report 2014-2015. World Economic Forum, Geneva, Switzerland, ISBN-13:978-92-95044-98-2, Pages: 565.

Sullivan, G.M. and R. Feinn, 2012. Using effect size-or why the $\mathrm{P}$ value is not enough. J. Graduate Med. Educ., 4: 279-282.

Tabachnick, B.G. and L.S. Fidell, 2012. Using Multivariate Statistics Plus Mysearchlab with Etext-Access Card Package. 6th Edn., Pearson Education, Upper Saddle River, New Jersey, USA., ISBN: 9780205885664 , Pages: 1024.

Teece, D.J., G. Pisano and A. Shuen, 1997. Dynamic capabilities and strategic management. Strategic Manage. J., 18: 509-533.

Tuan, N.P. and T. Yoshi, 2010. Organisational capabilities, competitive advantage and performance in supporting industries in Vietnam. Asian Acad. Manage. J., 15: 1-21. 
Usmani, F., 2013. Work Performance Data (WPD) and Work Performance Information (WPI). PM Study Circle, USA. https:/pmstudycircle. com/2013/ $10 /$ work-performance-data-wpd-and-workperforman ce-information-wpi.

Werts, C.E., R.L. Linn and K.G. Joreskog, 1974. Intraclass reliability estimates: Testing structural assumptions. Educ. Psychol. Meas., 34: 25-33.
World Bank, 2017. World Development Indicators. World Bank, Washington, USA., Pages: 146.

Wulf, K.D., 1999. The Role of the Seller in Enhancing Buyer-seller Relationships: Empirical Studies in a Retail Context. University of Central Florida, Orlando, Florida, Pages: 267.

Zhu, Z. and H. Huang, 2007. The cultural integration in the process of cross-border mergers and acquisitions. Intl. Manage. Rev., 3: 40-44. 